\title{
Data Mining in Production Management AND MANUFACTURING
}

\author{
MATSI, B.; OTTO, T.; LOUN, K. \& ROOSIMOLDER, L.
}

Abstract: Importance of data collecting and storing is growing in engineering sectors. Conventional databases have been developed to integrated systems, and traditional data analysis methods are often not the best alternative to be used. Data mining approaches have been used successfully in financing and banking, but it has a great potential also in manufacturing. Data mining implementations in production management and manufacturing are discussed in this paper. Integrating a datamining framework within the manufacturing information system will provide improved manufacturing decision making process and enhanced productivity.

Key words: data mining, manufacturing, production management
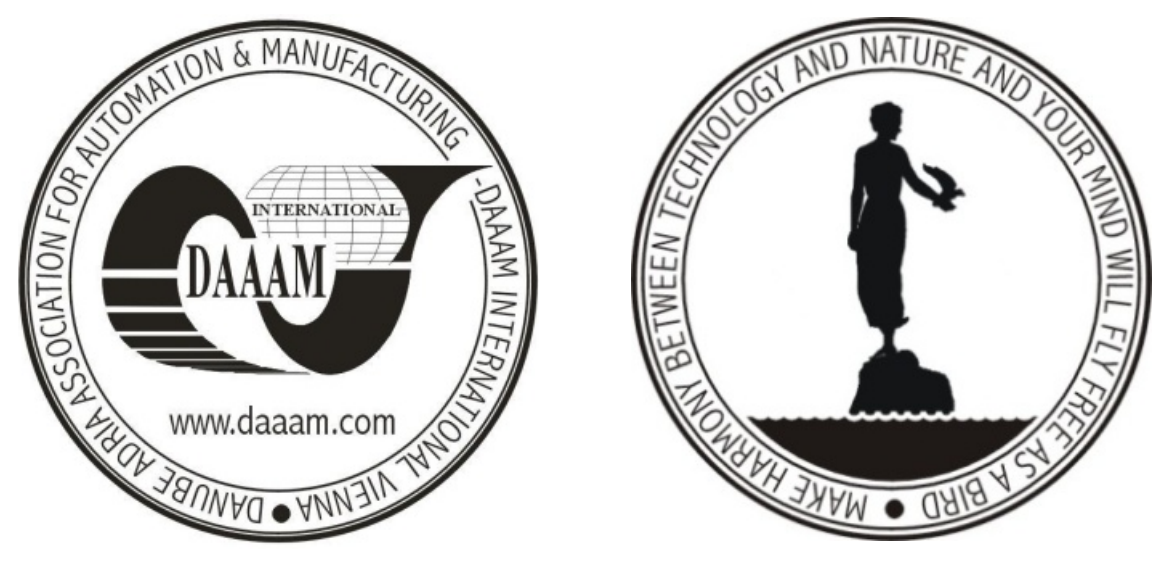

Authors' data: M.Sc. Matsi, B[irthe]; Ph.D. Otto, T[auno]; M.Sc. Loun, K[aia] \& Ph.D. Prof Roosimolder, L[embit], Tallinn University of Technology, Ehitajate tee 5, 19086, Tallinn, Estonia, birthe21@hotmail.com, tauno.otto@ttu.ee, kaia.loun@ttu.ee, lembitr@staff.ttu.ee

This Publication has to be referred as: Matsi, B[irthe]; Otto, T[auno]; Loun, K[aia] \& Roosimolder, L[embit] (2009). Data Mining in Production Management and Manufacturing, Chapter 11 in DAAAM International Scientific Book 2009, pp. 097106, B. Katalinic (Ed.), Published by DAAAM International, ISBN 978-3-90150969-8, ISSN 1726-9687, Vienna, Austria

DOI: 10.2507/daaam.scibook.2009.11 